\title{
The Body Is the Victory and the Defeat of Dreams
}

The body is the Victory of dreams

when shameless as water

it rises from slumber

marks and scars still asleep

these many signs

its dark olive groves

enamored

cool in the palm.

The body is the Defeat of dreams as it lies long and empty

(if you shout inside you hear the echo)

with its anemic hair

lovelorn of time

groaning, wounded

hating its motion

its primitive black

fades steadily

waking it's yoked to the briefcase

hanging from it suffering

for hours in the dust.

The body is the Victory of dreams

when it puts one foot in front of the other

and gains the solid space.

A place.

A heavy thud.

Death.

When the body gains its place

through death

in the public square

like a wolf with a burning muzzle

it howls "I want"

"I can't stand it" 


\section{"I threaten-I overthrow" \\ "My baby's hungry."}

The body gives birth to its justice and defends it.

The body makes the flower spits out the pip-death

tumbles down, flies

motionless whirls around the cesspool

(motion of the world)

in dream the body is triumphant

or is found naked in the streets

enduring;

it loses its teeth

it trembles erotically

its earth bursts like a watermelon

and it's finished.

\section{If I at Least Believed in God}

If $I$ at least believed in God

your hands would have

infinite interpretations

when they move

and lift me up to heaven

a heaven like Rilke's

with sad angels

blowing loneliness

down to earth

implied wings

timid in their speech

for they do not exist.

If $I$ at least believed in God my absurd insistence on self-torture on stepping out of the white circle of small happiness would have been explained to me I would have a stone in me 